\title{
Comparison of intubating conditions after induction with propofol combined with remifentanil or sufentanil in surgical tooth extraction: a randomized controlled trial
}

\section{Adeline Dolsan}

Centre Hospitalier Universitaire de Toulouse

\section{Laura Bruneteau}

Centre Hospitalier Universitaire de Toulouse

\section{Christine Roche}

Centre Hospitalier Universitaire de Toulouse

\section{Fabrice Ferré}

Centre Hospitalier Universitaire de Toulouse

\section{François Labaste}

Centre Hospitalier Universitaire de Toulouse

\section{Agnès Sommet}

Centre Hospitalier Universitaire de Toulouse

\section{Jean-Marie Conil}

Centre Hospitalier Universitaire de Toulouse

Vincent Minville ( $\nabla$ minville.v@chu-toulouse.fr)

Centre Hospitalier Universitaire de Toulouse https://orcid.org/0000-0003-0516-4939

\section{Study protocol}

Keywords: Intubating conditions, remifentanil, sufentanil, muscle relaxant

Posted Date: March 29th, 2019

DOI: https://doi.org/10.21203/rs.2.519/v1

License: (9) This work is licensed under a Creative Commons Attribution 4.0 International License. Read Full License 


\section{Abstract}

Background The aim of this study was to compare tracheal intubation conditions after anesthetic induction bolus of propofol-sufentanil or propofol-remifentanil. Methods A total of 70 patients, ASA I-II undergoing ambulatory surgery under general anesthesia with intubation for tooth extraction were randomly assigned in this double-blind study. They received either remifentanil ( $3 \mu \mathrm{g} / \mathrm{kg}$ ) or sufentanil $(0,3 \mu \mathrm{g} / \mathrm{kg})$ associated with $2,5 \mathrm{mg} / \mathrm{kg}$ of propofol for intubation. Intubating conditions score were compared using the Scandinavian scale. The primary outcome was the comparison of the percentage of excellent intubation conditions. The secondary outcomes were the percentage of patients with a decrease of over $20 \%$ in MAP or HR, time to have a spontaneous respiration, time between the end of the surgery and extubation, time to obtain an Aldrete score of 10. The percentage of patients having a pain score $>3$ or having laryngeal pain 15 minutes after arriving in PACU were also analyzed. Discussion Compared with the sufentanil group, intubating conditions were significantly better in the remifentanil group (51.4\% vs. $20 \% ; \mathrm{p}=0.0064)$. When using remifentanil, the hemodynamic conditions were good. Using remifentanil did not increase significantly the pain score or the laryngeal pain in recovery room. This is confirmed by the fact that morphine consumption was not significantly different in the two groups. Injecting remifentanil decreased significantly the time to obtain an Aldrete score of 10 . When intubating without muscle relaxants is required, intubating conditions are widely better when remifentanil is used in comparison with sufentanil. Study registration This study was approved by the research ethics board (protocol number 09.001.03, favorable opinion of the CPP Sud-Ouest et Outre-Mer 1 dated January 19, 2011) and written informed consent was obtained from each patient. This trial was registered at ClinicalTrials.gov (NCT01533662).

\section{Background}

Administering a muscle relaxant to supplement the drugs given to induce general anesthesia is not mandatory but usually facilitates tracheal intubation 1 . Muscle relaxants are allergenic and may produce prolonged neuromuscular blockade, delaying the return of spontaneous ventilation, and so are not justified for short surgical procedures 2. Moreover, the use of neuromuscular blocking drugs in general anesthesia is associated with an increase risk of postoperative pulmonary complications $3-5$. When rapid surgical procedures, such as tooth extraction, are realized, the use of muscle relaxants for intubation is undesirable. Recovery time is much longer than the time needed to perform the operation. Ambulatory turnover is an important factor in short procedures and is delayed when muscle relaxants are used.

Intubation where a muscle relaxant is not used entails a theoretical increased risk of lesions of the upper airways during the laryngoscopy when the intubating conditions are not good 6 . Where muscle relaxants are not used, it is desirable to administer alternative induction agents to provide good intubating conditions. Intubation without a muscle relaxant is an induction technique that is frequently used (450 000 a year in France in 1996) 7. The injection of opioids with propofol create good intubating conditions 8. The use of sufentanil is standard, but it is less effective for achieving excellent intubating conditions than a muscle relaxant 6 9. A bolus of $0.3 \mathrm{gg} . \mathrm{kg}-1$ provides excellent intubating conditions in $40 \%$ of 
cases 9. However, this dose delays the return of spontaneous ventilation and patient awakening. Furthermore, the maximum effects of sufentanil are not obtained until 6 minutes after injection 9.

Remifentanil is an opioid with good potential: its maximum effects are obtained between 60 and 90 seconds after injection; it has a short duration of action; and its elimination is independent of liver or renal metabolism 10. Several studies have reported that remifentanil, administered in combination with propofol where a muscle relaxant is not used, provides adequate intubating conditions, a good hemodynamic stability and early recovery $811-17$. Because remifentanil reaches adequate cerebral concentration levels more rapidly than does propofol, intubating and hemodynamic conditions are improved where remifentanil is injected after propofol 8 11-17. A dose of $3 \mathrm{~g} . \mathrm{kg}-1$ provides excellent intubating conditions in $80 \%$ of cases 1218 . However, this combination has never been compared with the standard propofol-sufentanil combination used as common practice in hospitals.

Thus the aim of this study was to compare tracheal intubation conditions after anesthetic induction by way of bolus injections of propofol combined with sufentanil as against propofol combined with remifentanil in patients undergoing surgical tooth extraction.

\section{Methods}

This single-center, prospective, randomized, double blind, intention-to-treat analysis, parallel group study was conducted at Toulouse University Hospital (France). All patients undergoing ambulatory surgery under general anesthesia with intubation for tooth extraction were enrolled in this study. All patients were aged between 18 and 60 , had ASA scores of 1 or 2 and were affiliated to a social security system. Exclusion criteria were: a history of chronic alcoholism or opiate use; treatment with beta-blockers or calcium channel blockers; paracetamol or ketoprofen allergies; being under protection of justice; and not wishing to participate in the study. This study was approved by the research ethics board (protocol number 09.001.03, favorable opinion of the CPP Sud-Ouest et Outre-Mer 1 dated January 19, 2011) and written informed consent was obtained from each patient. This trial was registered at ClinicalTrials.gov (NCT01910285).

The primary outcome was the comparison of the percentage of excellent intubation conditions using the Scandinavian scale. The secondary outcomes were the percentage of patients with a decrease of over $20 \%$ in MAP or HR, time to spontaneous respiration, time between the end of surgery and extubation and time to obtain an Aldrete score of 10 . The percentage of patients able to get into bed unassisted, with a VAS pain score $>3$ or with laryngeal pain 15 minutes after arriving in the PACU were also analyzed. Randomization of the patients was performed by the methodologist of the study using STATA software, and was centralized in the Clinical Pharmacology Service. A physician investigator opened the envelope corresponding to the patient's inclusion number and prepared 3 syringes numbered 1,2 and 3 . The remifentanil dose was prepared in a total volume of $20 \mathrm{~mL}$ by adding saline $0.9 \%$, and the sufentanil dose was prepared in a total volume of $10 \mathrm{~mL}$. Both care providers and the anesthesiologist assessing the outcomes were blinded to the study groups. The patients were randomized into two groups according 
to the opioid to be administered in combination with propofol $(2.5 \mathrm{mg} / \mathrm{kg})$ : the remifentanil group (Group R: $3 \mathrm{~g} / \mathrm{kg} ; \mathrm{n}=35$ ) and the sufentanil group (Group S: $0.3 \mathrm{~g} / \mathrm{kg} ; \mathrm{n}=35$ ). No premedication was administrated to any patients. On arrival in the operating room, each patient was infused and pre-oxygenated for 3 minutes. The chronometer was activated on injection of syringe 1 , which contained $0.3 \mathrm{~g} / \mathrm{kg}$ of sufentanil in the sufentanil group and $0.9 \%$ saline in the remifentanil group. After waiting 4 minutes, $3 \mathrm{mg} / \mathrm{kg}$ of propofol was injected in 30 seconds immediately followed by syringe 2, which was injected in 30 seconds. Syringe 2 contained $0.9 \%$ saline in the sufentanil group and $3 \mathrm{~g} / \mathrm{kg}$ of remifentanil in the remifentanil group. After waiting 30 seconds, mask ventilation was attempted. Laryngoscopy and nasalintubation were attempted using a Macintosh 4 laryngoscope blade and a 6.5 (men) or a 6 (women) endotracheal tube. A supplementary dose of propofol $(1 \mathrm{mg} / \mathrm{kg})$ could be injected; a maximum of twice if required. Patients who could not be intubated after these two supplementary doses of propofol were intubated with succinylchioline $1 \mathrm{mg} / \mathrm{kg}$. The anesthesiologist performing the intubation assessed ease of mask ventilation, jaw relaxation, oropharyngeal resistance to laryngoscopy, Cormack score, vocal cord position, patient reaction to insertion of the tracheal tube and cuff inflation (diaphragmatic movement and coughing), traction force and the need for a Sellick maneuver. The number of laryngoscopies, operators and alternative techniques were also recorded. These criteria were used to score intubating conditions using the Scandinavian Scale as excellent, good or poor (this is the recommended scale for the evaluation of intubating conditions) 19. The Intubation Difficulty Scale (IDS) was also calculated to determine the incidence of difficult intubation 20. Once intubated, controlled ventilation was initiated with a volume of $6-8 \mathrm{~mL} / \mathrm{kg}$. Maintenance of anesthesia was provided by Desflurane at MAC 1 . Ventilation was adapted to each patient to obtain exhaled $\mathrm{CO} 2$ between 45 and $50 \mathrm{mmHg}$. Syringe 3, which contained $0.05 \mathrm{~g} / \mathrm{kg}$ of sufentanil in the remifentanil group and $0.9 \%$ saline in the sufentanil group, was injected five minutes before incision. Spontaneous ventilation was initiated as soon as possible. Postoperative analgesia was injected as soon as the induction was finished with $1 \mathrm{~g}$ of paracetamol and $100 \mathrm{mg}$ of ketoprofen. Intraoperative analgesia was conducted using a $0.05 \mathrm{~g} / \mathrm{kg}$ bolus of sufentanil (to maintain spontaneous breathing frequency between 8 and 12 cycles $/ \mathrm{mn})$. Heart rate (HR), mean arterial pressure (MAP), peripheral oxygen saturation (SpO2) and exhaled $\mathrm{CO} 2$ were recorded every 2 minutes. Where systolic pressure was less than $80 \mathrm{mmHg}$, a bolus dose of $6 \mathrm{mg}$ of ephedrine was injected. Where HR was lower than 40 , a bolus dose of $10 \mathrm{~g} / \mathrm{kg}$ of atropine was injected. At the end of the surgery, all anesthetic agents were discontinued and the patients were ventilated with $100 \% 02$. The patients were extubated as soon as they opened their eyes or could answer a simple question. Patients were then transferred to the PACU where tramadol or morphine was administered as necessary. Tramadol was administered where the VAS pain score was $>3$ and morphine was administered if the VAS remained $>3$ after administration of the tramadol. The times elapsed from the injection of syringe 1 to laryngoscopy, cuff inflation, initiation of spontaneous respiration, surgical incision, end of surgery and tracheal extubation were recorded. Time to obtain an Aldrete score of 10 was recorded. Laryngeal pain, pain score and ability to get into bed unassisted were also recorded.

Data monitoring was done by the DRC (direction de la recherche Clinique) of the CHU Toulouse. Access to data was only limited to statistician of the study. 


\section{Statistical Analysis}

Demographic data and scores were abstracted and described through descriptive statistical analysis. A study of the distribution of the values was carried out using a Kolmogorov-Smirnov test, with in parallel, analyses of kurtosis and skewness. Results were expressed as the median and confidence interval $\mathrm{Cl} 95 \%$ [] for quantitative variables and in numbers and percentages ( ) for qualitative variables.

The study population was separated into 2 groups: the remifentanil group and the sufentanil group. Patient characteristics for the 2 groups were compared using:

- Non-parametric tests (Mann-Whitney U test) for continuous variables, because of the non-Gaussian distribution of the majority of the variables;

- Chi-squared test or Fisher's exact test for qualitative variables.

The non-parametric Mann-Whitney U-test was used was used to compare repeat HR and MAP measurement.

Sample size calculation

The hypothesis of our study is that the proportion of patients with perfect intubation conditions in the sufentanil group is $41 \% 9$ and $83 \% 1218$ in the remifentanil group. The expected difference is $42 \%$, with an Alpha-risk of $5 \%$ and a Beta of $90 \%$, in bilateral hypothesis, the number required for the study is 35 patients per group. The total number to be included in the study is therefore 70 subjects.

The study was carried out using MedCalc ${ }^{\circledR}$ statistical software version 15 (Mariakerke, Belgium). A $\mathrm{p}<$ 0.05 was considered statistically significant.

\section{Results}

A total of 70 patients were initially included in the study. Eight of the patients had to be excluded after inclusion (error in procedure, material problem). The randomization code was not broken and a further 8 patients were substituted. Of the 70 patients who completed the study there were an equal number in each group (Figure 1). There were no demographic differences between the two groups in term of age, weight, size, BMI and ASA score (Table 1).

Using the Scandinavian scale, the percentage of patients presenting excellent intubating conditions was statistically higher in the remifentanil group $(51.4 \%)$ than the in the sufentanil group $(20 \%)(p=0.0064)$. Furthermore, $31.4 \%$ of patients in the sufentanil group presented poor intubating conditions as against only $11.4 \%$ in the remifentanil group $(p=0.0133)$ (Figure 2$)$. There was no difference between the two groups in the incidence of difficult intubation according to the IDS scale.

Before induction, there were no significant differences in HR or MAP between the two groups. Figures 3 and 4 represent the variation of MAP profile and HR for the two groups. After intubation, MAP and HR 
increased but without significant difference between the two groups. Using remifentanil for induction did not significantly increase the pain score or laryngeal pain in the PACU. This is confirmed by the fact that morphine consumption did not differ significantly between the two groups (Table 2). Injecting remifentanil as opposed to sufentanil did not reduce the time to obtain spontaneous respiration or the time between the end of the surgery and extubation, but it significantly decreased the time to obtain an Aldrete score of 10 (Table 2). The percentage of patients able to get into bed unassisted was comparable between the two groups. We also noticed that there were more reactions to the insertion of the tracheal tube and cuff inflation in the sufentanil group than in the remifentanil group, since there was significantly more propofol re-injection in the sufentanil group ( $48.8 \%$ vs. $19.4 \%, \mathrm{p}=0.013)$.

\section{Discussion}

This study showed that a $3 \mathrm{~g} / \mathrm{kg}$ IV bolus dose of remifentanil in combination with $3 \mathrm{mg} / \mathrm{kg}$ of propofol, provided excellent intubating conditions according to the Scandinavian scale in $51.4 \%$ of patients as against only $20 \%$ in the sufentanil group.

To our knowledge, this is the first study to compare intubating conditions between sufentanil and remifentanil. We studied intubating conditions using the Scandinavian scale as the referential scale 19. For greater reliability, we studied excellent intubating conditions only (and did not consider good and excellent intubating conditions in our first outcome). There are many variations in the protocols studied in the literature (non-homogeneous distribution of doses, speed of administration of agents, injection durations and time elapsed between injection and intubation), which, together with age and gender differences between groups and the use of different assessment scales for assessing intubating conditions, may account for the differences observed between studies. In many studies, remifentanil is administered before propofol, whereas we administered the study drug as a rapid bolus after the induction agent as recommended 14 . Remifentanil and propofol doses vary in the studies. In each case a lower dose of remifentanil is compensated by a higher dose of propofol and vice versa. A minimum dose of remifentanil ( $3 \mathrm{~g} / \mathrm{kg}$ ) seems to be mandatory for successful intubation 812 18. In our study, intubating conditions using sufentanil were studied 6 minutes after its injection (to allow correlation between the onset of action of sufentanil and the laryngoscopy). This 6 minutes delay is hard to respect during daily sequence induction and creates an increased risk of difficult intubation. The use of remifentanil as a strategy of anesthesia for short procedures where a rapid ambulatory turnover is needed is therefore particularly appropriate. Moreover, we found that the Aldrete recovery score was significantly higher when remifentanil was used, as previously described.16 This result is highly relevant because it shows that induction with remifentanil allows faster output in the PACU, and helps to improve ambulatory turnover.

Several studies show that induction with remifentanil without muscle relaxants provides intubating conditions approaching that provided by succinylcholine; and also that remifentanil is superior to succinylcholine with regard to hemodynamic stability and recovery duration 15-17. In our study, the patients who were given remifentanil had a good hemodynamic tolerance. Induction using a propofol/remifentanil combination avoids the increase of intraocular pressure, and controls the 
hemodynamic stress response to laryngoscopy and intubation, in contrast to where a succinylcholine/propofol combination is used 15. According to these results and taking into account the side effects of succinylcholine, rapid sequence induction with remifentanil in place of succinylcholine in ASA 1 or 2 patients presenting an allergic risk, not suffering shock or those suffering hyper-intraocular pressure could be appropriate. But furthers studies are needed.

When intubating without using a muscle relaxant, the most effective drug combinations are those that include either alfentanil or remifentanil as the opioid 112122 . However, high doses of alfentanil are necessary. An initial bolus of $40 \mathrm{~g} / \mathrm{kg}$ seems to provide the best intubating conditions 22 . Where the dosage is below this level, up to $35 \%$ of patients may have closed vocal cords during laryngoscopy 22 . The relatively large doses of alfentanil recommended to facilitate tracheal intubation without muscle relaxant has a clinical duration of action that may be inappropriate for many procedures in ambulatory surgery 2324 . Moreover, alfentanil may cause muscle rigidity and in particular cardiovascular depression in high doses 24 . Remifentanil is 20 to 30 times more potent that alfentanil and its elimination half-time is $3.8-8.3$ minutes. Compared to alfentanil, remifentanil's effect reduces much more quickly after intubation, which is an important advantage over alfentanil, especially in short procedures and ambulatory surgery. The use of fentanyl for intubating without muscle relaxants lead to good intubation scores in only $17 \%$ of patients 23 .

Hemodynamic tolerance was similar and acceptable in both groups of our study. MAP values decreased significantly by more than $20 \%$ after induction in the remifentanil group but never dropped below 67 $\mathrm{mmHg}$. There was no significant increase in the requirement for ephedrine administration across the two groups. HR never dropped below $20 \%$ in either group. Several studies reported similar acceptable decreases in MAP or HR (using a value of 30\%) when using remifentanil and propofol 812141518 . Hanna et al. (13)showed that induction with $4 \mathrm{~g} / \mathrm{kg}$ of remifentanil injected after $2 \mathrm{mg} / \mathrm{kg}$ of propofol caused a significant change in HR. This dose of remifentanil is higher than the one we used.

With respect to laryngeal pain after intubation, remifentanil seems to be relatively safe. Only $46.4 \%$ of the patients intubated with remifentanil in our study had laryngeal pain after intubation against $43 \%$ of the patients intubated with rocuronium. 6 This is in contrast to $53.6 \%$ suffering laryngeal pain in our sufentanil group and $57 \%$ in Combes et al. alfentanil group. 6

There are limitations in our study. First, our results are only applicable to ASA 1 and 2 patients aged from 18 to 60 years. Indeed, hemodynamic tolerance may be different in ASA 3 or 4 patients, particularly those suffering from serious heart disease. Hemodynamic tolerance may be also different in the elderly or patients suffering hypovolemia. Authors found that combined with $1 \mathrm{mg} / \mathrm{kg}$ propofol, $1.39 \mathrm{~g} / \mathrm{kg}$ of remifentanil resulted in acceptable intubating conditions within 60 seconds in $95 \%$ of elderly patients. 25 MAP and HR decreased significantly after propofol and remifentanil administration, but were within $30 \%$ of baseline values. 25 Secondly, there was no anticipated risk of difficult intubation for any of the patients. A study of remifentanil used in combination with propofol for anesthetic induction without using muscle relaxants in a population at high risk of difficult intubation could be the next step. 
In conclusion, intubating conditions are significantly better where remifentanil is used in comparison with sufentanil where muscle relaxants are not used: excellent intubating conditions in $51.4 \%$ of cases using remifentanil as opposed to $20 \%$ for sufentanil. The hemodynamic conditions were quite acceptable since MAP remained above $67 \mathrm{mmHg}$ and there was no statistical diminution of HR. The pain score was not modified and laryngeal pain was comparable to that described where muscle relaxants are used. Finally, the time elapsed in the PACU was decreased which can facilitate ambulatory turnover. Therefore, we highly recommend the use of remifentanil for ASA 1 and 2 patients aged between 18 and 60 where it is necessary to intubate without muscle relaxants.

\section{Abbreviations}

MAP: mean arterial pressure; HR: heart rate; VAS: visual analog scale; PACU: post anesthetic care unit; Intubation IDS: Difficulty Scale; Sp02: oxygen saturation; BMI: body mass index; ASA: American society of anesthesiology; IV: intra venous

\section{Declarations}

Ethic approval: This study was approved by the research ethics board (protocol number 09.001.03, favorable opinion of the CPP Sud-Ouest et Outre-Mer 1 dated January 19, 2011) and written informed consent was obtained from each patient. This trial was registered at ClinicalTrials.gov (NCT01910285 dated July 29, 2013).

Funding: Support was provided solely from institutional and department sources.

\section{Authors' contributions}

Conceived and designed the experiments: CR, VM. Performed the experiments: CR, LB, FF, AD. Wrote the paper: JMC, AD, LB, CR, VM.

Declaration of interests: None declared.

Funding. CHU Toulouse supported this work

Acknowledgement: The authors thank Leonie Smith for the English editing of this article.

\section{References}

1. Baillard C, Adnet F, Borron SW, et al. Tracheal intubation in routine practice with and without muscular relaxation: an observational study. Eur J Anaesthesio/ 2005;22:672-7

2. Heerdt PM, Sunaga $\mathrm{H}$, Savarese JJ. Novel neuromuscular blocking drugs and antagonists. Current Opinion in Anaesthesiology 2015;28:403-10 
3. Bulka CM, Terekhov MA, Martin BJ, Dmochowski RR, Hayes RM, Ehrenfeld JM. Nondepolarizing Neuromuscular Blocking Agents, Reversal, and Risk of Postoperative Pneumonia. Anesthesiology 2016;125:647-55

4. Grosse-Sundrup M, Henneman JP, Sandberg WS, et al. Intermediate acting non-depolarizing neuromuscular blocking agents and risk of postoperative respiratory complications: prospective propensity score matched cohort study. BMJ 2012;345:e6329

5. Kirmeier E, Eriksson LI, Lewald $\mathrm{H}$, et al. Post-anaesthesia pulmonary complications after use of muscle relaxants (POPULAR): a multicentre, prospective observational study. Lancet Respir Med 2018;

6. Combes $\mathrm{X}$, Andriamifidy L, Dufresne $\mathrm{E}$, et al. Comparison of two induction regimens using or not using muscle relaxant: impact on postoperative upper airway discomfort. Br J Anaesth 2007;99:276-81

7. Laxenaire MC, Auroy $Y$, Clergue F, Péquignot $F$, Jougla $E$, Lienhart A. [Organization and techniques of anesthesia]. Annales Françaises d'Anesthésie et de Réanimation 1998;17:1317-23

8. Alexander R, Olufolabi AJ, Booth J, El-Moalem HE, Glass PS. Dosing study of remifentanil and propofol for tracheal intubation without the use of muscle relaxants. Anaesthesia 1999;54:1037-40

9. Adamus M, Koutná J, Gabrhelík T, Zapletalová J. [Tracheal intubation without muscle relaxant--the impact of different sufentanil doses on the quality of intubating conditions: a prospective study]. Cas Lek Cesk 2008;147:96-101

10. Minto CF, Schnider TW, Shafer SL. Pharmacokinetics and pharmacodynamics of remifentanil. II. Model application. Anesthesiology 1997;86:24-33

11. Alexander R, Booth J, Olufolabi AJ, El-Moalem HE, Glass PS. Comparison of remifentanil with alfentanil or suxamethonium following propofol anaesthesia for tracheal intubation. Anaesthesia 1999;54:1032-6

12. Demirkaya M, Kelsaka E, Sarihasan B, Bek Y, Üstün E. The optimal dose of remifentanil for acceptable intubating conditions during propofol induction without neuromuscular blockade. J Clin Anesth 2012;24:392-7

13. Bouvet L, Stoian A, Rimmelé T, Allaouchiche B, Chassard D, Boselli E. Optimal remifentanil dosage for providing excellent intubating conditions when co-administered with a single standard dose of propofol. Anaesthesia 2009;64:719-26

14. Trabold F, Casetta M, Duranteau J, et al. Propofol and remifentanil for intubation without muscle relaxant: the effect of the order of injection. Acta Anaesthesiol Scand 2004;48:35-9

15. Hanna SF, Ahmad F, Pappas ALS, et al. The effect of propofol/remifentanil rapid-induction technique without muscle relaxants on intraocular pressure. J Clin Anesth 2010;22:437-42 
16. Gulhas N, Topal S, Erdogan Kayhan G, et al. Remifentanil without muscle relaxants for intubation in microlaryngoscopy: a double blind randomised clinical trial. Eur Rev Med Pharmacol Sci 2013;17:196773

17. Naziri F, Amiri HA, Rabiee M, et al. Endotracheal intubation without muscle relaxants in children using remifentanil and propofol: Comparative study. Saudi J Anaesth 2015;9:409-12

18. Stevens JB, Wheatley L. Tracheal intubation in ambulatory surgery patients: using remifentanil and propofol without muscle relaxants. Anesth Analg 1998;86:45-9

19. Fuchs-Buder T, Claudius C, Skovgaard LT, et al. Good clinical research practice in pharmacodynamic studies of neuromuscular blocking agents II: the Stockholm revision. Acta Anaesthesiol Scand. 2007. p. $789-808$

20. Adnet F, Borron SW, Racine SX, et al. The intubation difficulty scale (IDS): proposal and evaluation of a new score characterizing the complexity of endotracheal intubation. Anesthesiology 1997;87:1290-7

21. Hanci V. Tracheal intubation without use of muscle relaxants: comparison of remifentanil and alfentanil. Anesth Pain Med 2012;1:210-1

22. Scheller MS, Zornow MH, Saidman LJ. Tracheal intubation without the use of muscle relaxants: a technique using propofol and varying doses of alfentanil. Anesth Analg 1992;75:788-93

23. Jabbour-Khoury SI, Dabbous AS, Rizk LB, et al. A combination of alfentanil-lidocaine-propofol provides better intubating conditions than fentanyl-lidocaine-propofol in the absence of muscle relaxants. Can J Anaesth 2003;50:116-20

24. Klemola UM, Mennander S, Saarnivaara L. Tracheal intubation without the use of muscle relaxants: remifentanil or alfentanil in combination with propofol. Acta Anaesthesiol Scand 2000;44:465-9

25. Goo E-K, Oh A-Y, Cho S-J, Seo K-S, Jeon Y-T. Optimal remifentanil dosage for intubation without muscle relaxants in elderly patients. Drugs Aging 2012;29:905-9

\section{Tables}

Table 1: Demographic data 


\begin{tabular}{llll} 
& Global population & Sufentanil & Rémifentanil \\
& $\mathrm{n}=70$ & $\mathrm{n}=35$ & $\mathrm{n}=35$ \\
\hline Median [95 Cl] & Median [95 Cl] & Median [95 Cl] \\
\hline Age & $24[21-25)$ & $24[21-26]$ & $24[20-26]$ \\
\hline Measured weight & $65[60-68]$ & $68[62-73]$ & $60[57-67]$ \\
\hline Ideal weight & $61(59-63]$ & $62[59-64]$ & $60[59-64]$ \\
\hline Size & $167[165-170]$ & $167[164-171]$ & $167[164-171]$ \\
\hline BMI & $23[22-24]$ & $23[22-24]$ & $22[21-23]$ \\
\hline ASA & $1[1-1]$ & $1[1-1]$ & $1[1-1]$
\end{tabular}

There was no significant difference between groups. $B M I=$ body mass index; $A S A=$ American Society of Anesthesiologists physical status; $95 \mathrm{Cl}=$ confident interval

Table 2: Study of the secondary outcomes 


\begin{tabular}{|c|c|c|c|}
\hline & $\begin{array}{l}\text { Sufentanil } \\
n=35\end{array}$ & $\begin{array}{l}\text { Remifentanil } \\
\mathrm{n}=35\end{array}$ & $\mathbf{p}$ \\
\hline & Median [95 Cl] & Median [95 Cl] & \\
\hline IDS score & $1[0-2]$ & $1[0-1]$ & 0,4127 \\
\hline Time to have a spontaneous respiration (seconds) & $\begin{array}{l}2004[1721,2- \\
2581,4]\end{array}$ & $\begin{array}{l}1978,5[1800,6- \\
2276,2]\end{array}$ & 0,7344 \\
\hline $\begin{array}{l}\text { Time between the end of the surgery and extubation } \\
\text { (seconds) }\end{array}$ & $319[231-397]$ & $\begin{array}{l}351[297,8- \\
408]\end{array}$ & 0,4239 \\
\hline \multirow[t]{2}{*}{ Time to obtain an Aldrete score of 10 (seconds) } & $\begin{array}{l}5310[4800 \text { to } \\
6203,6]\end{array}$ & $\begin{array}{l}4650[4059,5- \\
5660,5]\end{array}$ & $0,0293 *$ \\
\hline & Sufentanil & Rémifentanil & \\
\hline $\begin{array}{l}\% \text { of patients with a decrease of over } 20 \% \text { in MAP } \\
\text { between T12 et T0 }\end{array}$ & $17(27,8 \%)$ & $28(62,2 \%)$ & $0,0064^{*}$ \\
\hline $\begin{array}{l}\% \text { of patients with a decrease of over } 20 \% \text { in HR } \\
\text { between T12 et T0 }\end{array}$ & $13(44,8 \%)$ & $16(55,2 \%)$ & 0,4699 \\
\hline$\%$ of patients going to bed alone & $22(44 \%)$ & $28(56 \%)$ & 0,1581 \\
\hline$\%$ of patients having a pain score $>3$ & $19(55,9 \%)$ & $24(66,7 \%)$ & 0,3577 \\
\hline $\begin{array}{l}\% \text { of patients having laryngeal pain } 15 \text { minutes after } \\
\text { arriving in recovery room }\end{array}$ & $15(53,6 \%)$ & $13(46,4 \%)$ & 0,5582 \\
\hline$\%$ of patients who needs morphin in recovery room & $7(20,6 \%)$ & $4(11,8 \%)$ & 0,3268 \\
\hline
\end{tabular}

$95 \mathrm{Cl}=$ confident interval, IDS= intubation difficulty scale; $\mathrm{MAP}=$ mean arterial pressure, $\mathrm{HR}=$ heart rate

\section{Figures}




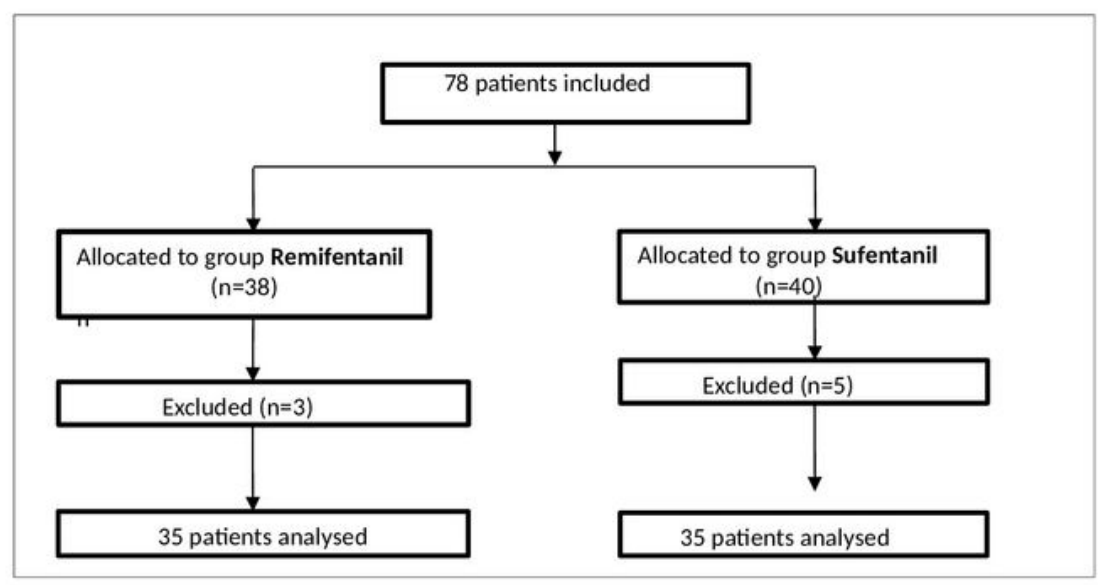

Figure 1

Flow chart of the study. 


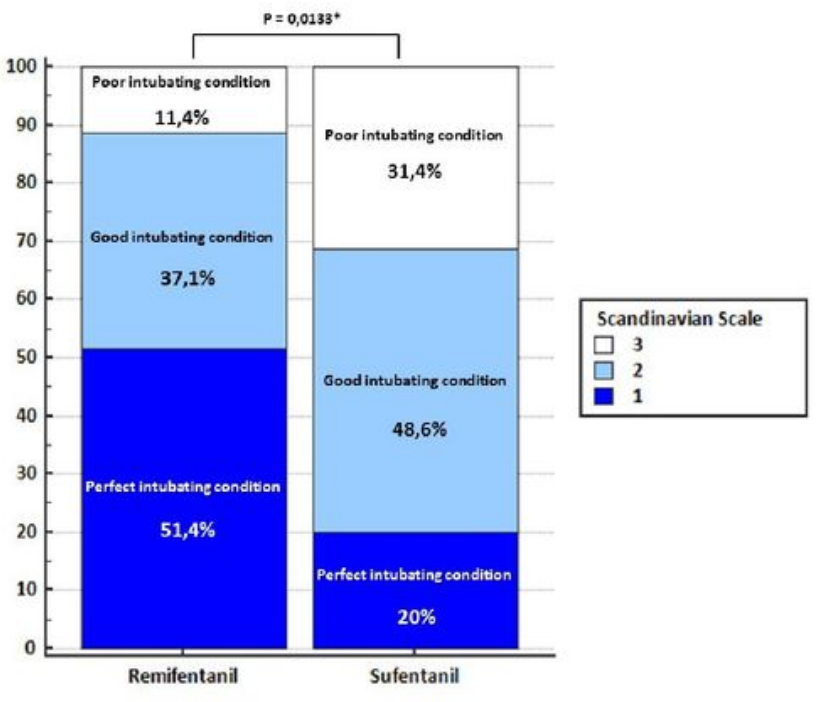

\section{Figure 2}

Intubating conditions using the Scandinavian Scale 1: excellent intubating condition 2: good intubating condition 3: poor intubating condition 


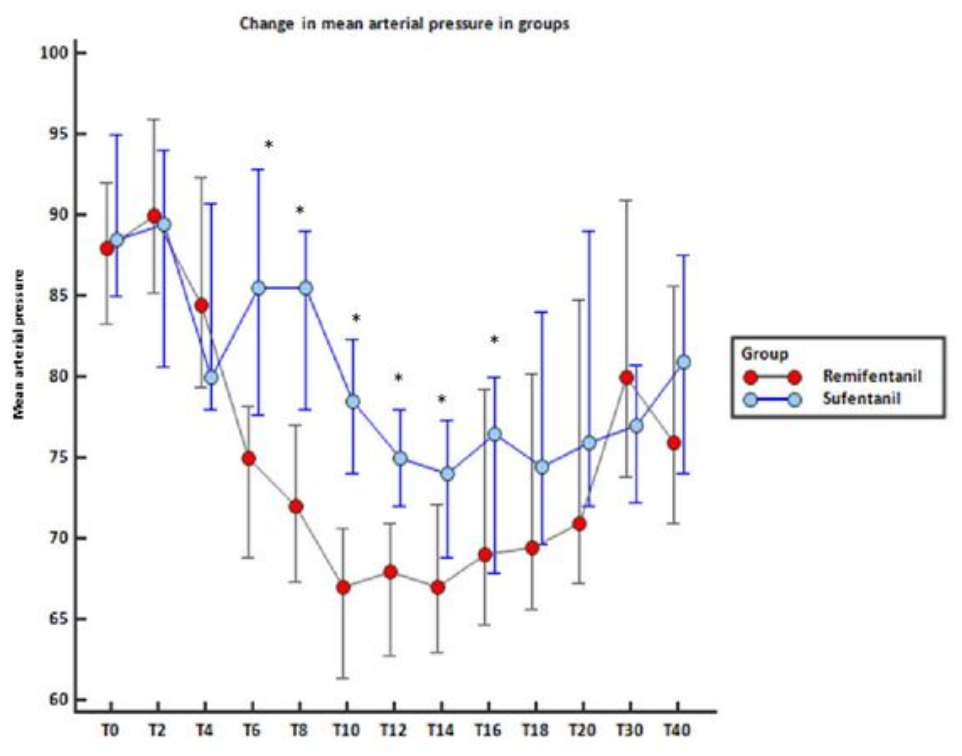

\section{Figure 3}

Change in mean arterial pressure (MAP) in the 2 groups The values recorded at T0 are the pre-induction ones. Propofol was injected at T4. T6 represents the values recorded after the injection of remifentanil (or saline serum for the sufentanil group). Intubation was realized between T6 and T8. MAP and HR decreased in the two groups after induction. *: statistically different when comparing the remifentanil and the sufentanil group 


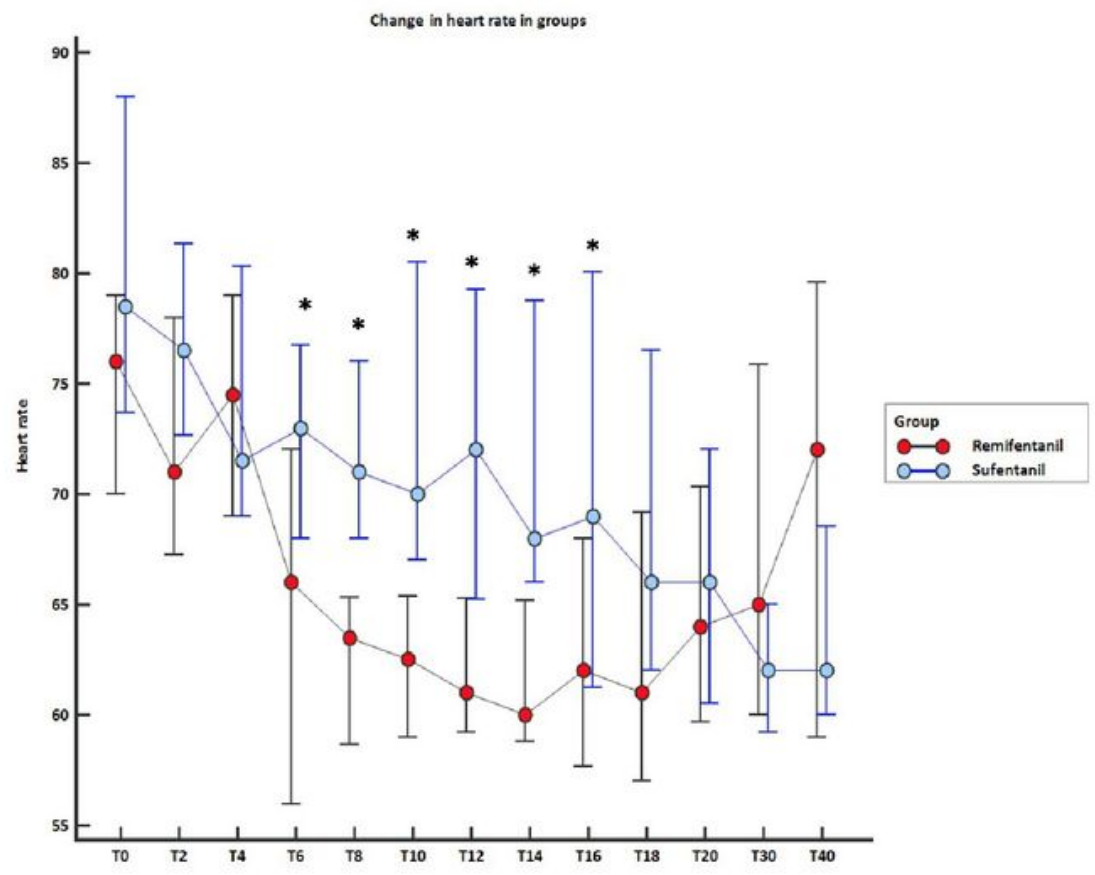

\section{Figure 4}

Change in heart rate (HR) in groups. The values recorded at T0 are the pre-induction ones. Propofol was injected at T4. T6 represents the values recorded after the injection of remifentanil (or saline serum for the sufentanil group). Intubation was realized between T6 and T8. MAP and HR decreased in the two groups after induction. *: statistically different when comparing the remifentanil and the sufentanil group Supplementary Files 
This is a list of supplementary files associated with this preprint. Click to download.

- supplement1.doc 